\title{
CYSTICERCOSIS CELLULOSAE OF THE OPTIC DISC WITH GENERALIZED CYSTICERCOSIS*
}

\author{
BY \\ Y. S. BAWA $†$ AND P. L. WAHI \\ From the Department of Clinical Medicine, Medical College and Rajendra Hospital, Patiala, \\ Punjab, India
}

CysticERCOSIS of the brain has been known for centuries and most of the earlier reports came from central Europe. MacArthur (1934) and Dixon and Hargreaves (1944) have aroused interest in the problem of cerebral cysticercosis recently.

From India very many reports have been published about the cerebral manifestations of cysticercosis (Dogra and Ahern, 1935; Menon and Veliath, 1940; McRobert, 1944; Subramaniam, 1946; Gault and Balasubrahmanyan, 1948; Raman, Ramamurthi, and David, 1950; Dave, 1950; Reddy, 1951; Chandy and Vaishnava, 1958) and some have emphasized unusual manifestations such as marked muscular development (Subramaniam, 1946) and pseudohypertrophic muscular dystrophy (McGill, 1947; Singh and Jolly, 1957). Most of these reports have come from southern India, though many of MacArthur's cases came from army cantonments of northern India. Cases have been reported from the Punjab by Singh and Jolly (1957) and Wahi and Chugh (1958). Though cerebral cysticercosis is a well-known entity, cysticercosis of the eye (alone or in combination with cerebral or generalized cysticercosis) is less often seen (Meyerson and Pienaar, 1961; Balakrishnan, 1961). Retinal and vitreous cysticercosis (Reddy and Reddy, 1957) and cysts in the anterior chamber have been described, but a cyst situated directly over the optic disc is very rare.

We record below one such case presenting with generalized cysticercosis and cysticercosis cellulosae of the optic disc.

\section{Case Report}

A police constable aged 26 years was admitted to hospital on July 7, 1959, with a history of attacks of unconsciousness for the last $2 \frac{1}{2}$ years and marked diminution of vision for the last $2 \frac{1}{2}$ months. The first attack came on without warning while he was on duty. He was then quite well for about 11 months until he had an attack of giddiness lasting about 10 minutes with no loss of consciousness. In a third attack 8 months later, after a short phase of giddiness, the head turned towards the left with sudden jerky movements. Since then the attacks had been frequent even up to two or three a day. A typical attack began with giddiness, slight vertigo, and jerky movements of the head, followed by head turning to the left, unconsciousness, and sleepiness. There had never been any transitory weakness of the limbs.

* Received for publication December 20, 1961

$\dagger$ Present address: Department of Clinical Medicine, Medical College, Amritsar. 
About 2 months before admission he had become blind in the right eye.

His past and family history did not reveal anything significant. There was no history of intestinal worms, but he had frequently taken improperly cooked pork.

Examination.-He was a well built and well nourished individual. There was no abnormality apart from multiple subcutaneous nodules varying in size from a small pea to a small almond. The nodules were not tender to touch. The vision was markedly diminished in the right eye and with constriction of the visual fields. There was no neurological defect, and the heart, lungs and abdomen were normal.

Laboratory Investigations.-Hb 12.9 per cent. Total and differential leucocyte counts, urine, and stools normal. Erythrocyte sedimentation rate $7 \mathrm{~mm}$. first hour (Westergren). Total eosinophil count $120 / \mathrm{cmm}$. The stools were examined thoroughly and repeatedly but no tape-worm was seen. Serological tests for syphilis were negative. The cerebrospinal fluid was clear, 120 drops/minute. Queckenstedt test positive. On microscopic examination, a few red blood cells and occasional lymphocytes were seen. Plasma proteins $35 \mathrm{mg}$. per cent; globulin negative; sugar $52 \mathrm{mg}$. per cent.; chloride $712 \mathrm{mg}$. per cent.

The fundus (Figure) was examined by the professor of ophthalmology.

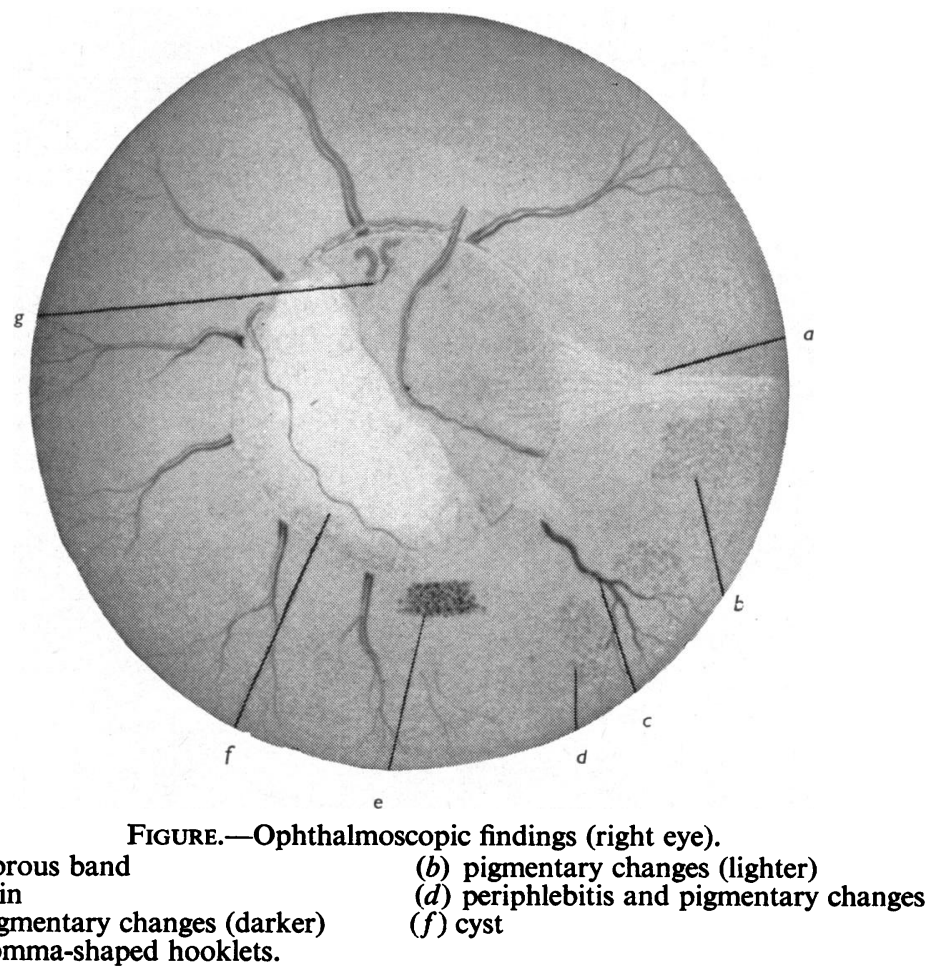

A skiagram of the soft tissues of the neck showed a few calcified cysts, and a histological examination of one of these nodules showed findings typical of Cysticercus cellulosae.

Progress. - He was given gardinal tablets $\frac{1}{2}$ gr. three times a day. The major fits were well controlled but he occasionally had a feeling of giddiness and a tingling sensation in the right thumb, often accompanied by a right temporal headache. Examination during these episodes revealed no neurological defect. 
Result.-On December 5 he left the ward with permission to draw his pay and the next day one of his relatives came to inform us that he had had a major fit and died suddenly at the pay window.

\section{Discussion}

Cysticercosis as a cause of epilepsy of generalized and focal type is well recognized. It is also known to produce bizarre neurological manifestations depending upon the location of the cerebral cyst or cysts (racemose or otherwise) and the resultant changes in the intracranial pressure and cerebrospinal fluid.

Retinal involvement is not uncommon and the characteristic ophthalmological picture may at times lead to the correct diagnosis. The present case is interesting because a cyst was found on the optic disc as well as the subcutaneous and cerebral cysticercosis. This intra-ocular cyst was not due to invasion of the disc but seemed to arise from the optic disc.

Though the vision deteriorated the cyst did not excite any foreign body reaction or lead to panophthalmitis.

The cerebral cysts could not be seen radiologically but their presence was proved by the unusual fits to which the patient was subject. The terminal episode though seemingly very dramatic is not an uncommon outcome in cerebral cysticercosis. Sudden modifications in the intracranial pressures may lead to derangement of vital medullary centres and so cause sudden death. In this case the patient was dubbed a "malingerer" or a case of functional neurosis before the correct diagnosis was made.

\section{Summary}

A case is described of Cysticercus cellulosae affecting the optic disc with generalized cysticercosis.

We are grateful to Dr. Prem Chandra, Professor of Ophthalmology, Medical College, Patiala, for the report on the patient's fundus and to Shri Sharma for the diagram of the ophthalmoscopic findings.

\section{REFERENCES}

Balakrishnan, E. (1961). Brit. J. Ophthal., 45, 150.

Chandy, J., and VaIshnava, S. (1958). Ind. J. Child Hlth, 7, 441.

DAVE, C. J. (1950). Ind. med. Gaz., 85, 92.

Dixon, H. B. F., and HARGreaves, W. H. (1944). Quart J. Med., n.s. 13, 107.

DOGRA, J. R., and AHERN, D. M. (1935). Ind. med. Gaz., 70, 510.

Gault, E. W., and Balasubrahmanyan, M. (1948). J. Path. Bact., 60, 505.

MACARTHUR, W. P. (1934). Trans. roy. Soc. trop. Med. Hyg., 27, 343.

MCGILL, R. G. (1947). Ind. J. med. Sci, 1, 109.

MCROBERT, G. R. (1944). Ind. med. Gaz., 79, 399.

Menon, T. B., and Veliath, G. D. (1940). Trans. roy. Soc. trop. Med. Hyg., 33, 537.

MeYerson, L., and PienaAR, B. T. (1961). Brit.J. Ophthal., 45, 148.

RAMAN, T. K., RAMAMURTHI, B., and DaVID, C. V. (1950). Ind. Physch, 9, 207.

REDDY, D. J. (1951). Ind. med. Gaz., 86, 14.

REDDY, P. S., and RedDY, D. B. (1957). Curr. med. Pract., 1, 642.

SinGH, A., and Jolly, S. S. (1957). Ind. J. med. Sci., 11, 98.

SubramaniaM, R. (1946). Ind. med. Gaz., 81, 64.

WAHI, P. L., and Chugh, K. S. (1958). Postgrad. med. J. (India), 7, 233. 